\title{
Teaching Competencies for Community Preceptors
}

Darin Brink, MD; Deb Simpson, PhD; Byron Crouse, MD; Jeffrey Morzinski, PhD, MSW; Douglas Bower, MD; Ruth Westra, DO, MPH

\begin{abstract}
BACKGROUND AND OBJECTIVES: Although community physicians provide one-fourth of the outpatient training received in medical school, usually there is no formal training of the preceptor. Currently there is no agreed-upon list of teaching competencies for community physician-preceptors. Using a modified Delphi process, the authors aimed to identify core teaching competencies for community preceptors for use in training and evaluation.
\end{abstract}

METHODS: A medical educator and three faculty members with expertise in faculty development created a list of teaching competencies organized in five domains. These competencies were finalized through a multiround modified Delphi technique with key stakeholder groups including (1) nonphysician medical educators, (2) academic physicians involved in faculty development, (3) community physicians who regularly precept medical students, (4) family medicine residents, (5) third-year medical students in a 9-month-long longitudinal clerkship. Proposed competencies were retained if $70 \%$ of the participants ranked it as "very or extremely important."

RESULTS: In the first round, 24 competencies were evaluated by 40 physician preceptors participating in a rural faculty development conference. These were refined, and four additional competencies were added by the cohort. Subsequent rounds utilized a survey approach with broader audiences resulting in a final list of 21 competencies in five domains.

CONCLUSIONS: Five competency domains with 21 teaching competencies can now be used to guide community preceptors' training and evaluation.

(Fam Med. 2018;50(5):359-63.)

doi: 10.22454/FamMed.2018.578747

$\mathbf{T}$ he majority of medical students receive some of their training in community settings. ${ }^{1-6}$ Most American medical schools rely on practicing physicians in the community (hereafter referred to as community preceptors) to teach their students, particularly in the first and second year of medical school and for primary care clerkships. ${ }^{1,7,8}$ Most of these preceptors, while trained and experienced in education, ${ }^{8-10}$ and preceptors, the trainees' sponsoring organizations, and accreditation standards emphasize faculty development as one of their greatest needs. ${ }^{8,11,12}$ Much work has already been done to identify the needs of community preceptors, ${ }^{4,12,13}$ physicians, have no formal training to provide formal training for preceptors, ${ }^{6,9,14}$ to help integrate students into busy clinical practices, ${ }^{15}$ and to assess the instructional quality of a clinical site, ${ }^{16,17}$ but as yet there is no consensus on the key criteria for identifying, training, or evaluating community preceptors. While there are established skills and behaviors (ie, milestones, competencies, observable behaviors, entrustable professional activities, etc) for medical students, ${ }^{18,19}$ residents, ${ }^{20}$ and for academic faculty ${ }^{21,22}$ there are currently no agreed-upon skills, attitudes, and behaviors for the diverse cadre of physician preceptors who teach students and residents.

Clearly defined preceptor competencies are needed to provide the foundation for preceptor development and evaluation activities.

We sought to identify core community preceptor competencies to support preceptor needs assessment, development, and evaluation. ${ }^{21}$

\section{Methods}

The Delphi technique is a common method of semiquantitative research in the social sciences and in healthrelated education. ${ }^{23}$ Typically, a small group of experts first defines a list

From the University of Minnesota, Minneapolis, MN (Dr Brink); University of Wisconsin, Madison, WI (Drs Simpson and Crouse); Medical College of Wisconsin, Milwaukee, WI (Drs Morzinski and Bower); and University of Minnesota, Duluth, MN (Dr Westra). 
(eg, proposed curriculum, objectives, priorities, competencies, etc). Next, this list is sent out to a panel of stakeholders whose expert opinions and critiques are aggregated in an anonymous fashion. This takes places in a number of rounds in which each solicited expert rates and evaluates the list independently of the cohort. ${ }^{23,24}$ Lindemann suggests that this approach provides greater objectivity since there is no peer pressure to conform to the opinion of the group..$^{25}$ When no previous standard exists or where there is ambiguity in practice, the Delphi technique supports content validity of the product.

Building on the competency movement in medical education, we reviewed Srinivasan's 10 educator competencies and their associated knowledge, skills, and attitudes which includes the six Accreditation Council for Graduate Medical Education (ACGME) competencies (ie, medical knowledge, learner-centeredness, interpersonal and communication skills, professionalism and role modeling, practice-based reflection, system-based practice) and four specialized competencies for faculty with educational program-level roles (program design and implementation, evaluation and scholarship, leadership and mentorship). ${ }^{21} \mathrm{~A}$ medical educator and three faculty members with expertise in faculty development extracted relevant medical student preceptor competencies from Srinivasan's work and from other relevant literature. Five competency domains and 24 competencies were identified. To obtain consensus from a large group of stakeholders, we used the Delphi method twice with two diverse groups and also sought validation from medical student educators attending a national conference (Figure 1). The final product is a listing of the domains and the desired competencies for community preceptors of medical students. This study protocol was reviewed and exempted by the University of Minnesota institutional review board.

\section{Results}

\section{Modified Delphi Method}

Phase 1, Round 1: The 24-item preceptor competency list was presented to 40 family medicine educators and physicians who participated in a workshop at the annual Wisconsin Collaborative for Rural GME (WCRGME) Faculty Development Conference in September 2016. This annual meeting helps train physicians to be better educators and is attended by both full-time academic faculty from Wisconsin's medical schools and residencies as well as rural community physicians who routinely precept medical students. The 40 attendees were divided into five groups which evaluated one of the five competency domains. They were asked to further develop the competencies assigned to each of the competency domains. The participants suggested four additional competencies to add to the original list of 24 , for a total of 28 competencies.

Phase 1, Round 2: The $28 \mathrm{com}$ petencies were then emailed to the WCRGME workshop participants to complete a modified Delphi technique. ${ }^{26}$ Thirty-seven of the original 40 participants responded (93\%). Using a 5-point Likert scale format ("no importance" to "extremely important") participants ranked the competencies and added comments. Items that were rated as "very important" or "extremely important" by $70 \%{ }^{23}$ or more of the panelists were retained, for a total of 26 . The product of this session was also edited for clarity and redundancy based on feedback from the participants.

Phase 2, Round 1: We wanted to obtain consensus on the appropriateness and usefulness of these competencies from a larger number of stakeholders, therefore in phase 2 we invited a total of 383 people to review and rate the importance of the 26 competencies. These people represent a convenience sample drawn from five groups. Group one was a list of community physicians who regularly precept medical students for the family medicine clerkship at the University of Minnesota, the University of Wisconsin, or the Medical College of Wisconsin. Group two was a list of family medicine residents in one of five University of Minnesota affiliated programs. Group three was a list of third-year medical students in a 9-month-long longitudinal clerkship at the University of Minnesota. Group four was a list of academic physicians involved in faculty development at the University of Minnesota. Group five was a list of nonphysician medical educators at the University of Wisconsin school or the Medical College of Wisconsin. Participants received an

Figure 1: Modified Delphi Process for Developing the Community Preceptor Teaching Competencies

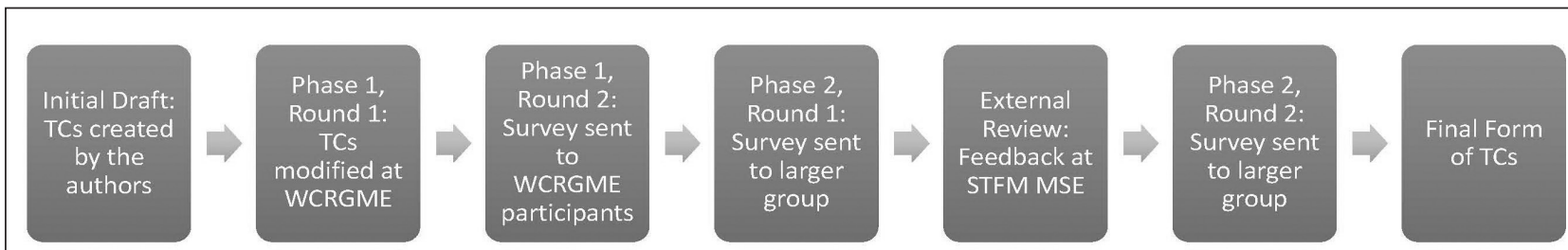

STFM MSE: Society of Teachers of Family Medicine Medical Student Education conference

TCs: teaching competencies

WCRGME: Wisconsin Collaborative for Rural GME Faculty Development conference 
email with a weblink via Qualtrics and were asked to complete the survey within a week, with a follow-up email to nonresponders after 7 days. Anonymity was maintained throughout the study, so participants were unaware of the other panel members' identities and all responses were given equal voting power. Of the 343 students, residents, educators, and physicians who received an email invitation to participate in our study, 106 people responded and completed the survey (31\%).

As in prior rounds, respondents rated each of the 26 competencies using a 5-item Likert scale format ("no importance" to "extremely important"). Again, any item receiving an importance rating of less than or equal to "moderately important" by more than $30 \%$ of the respondents was eliminated, resulting in 21 competencies being retained.

Phase 2, External Validation: To obtain external validation from an outside audience we presented this second iteration of our competencies during an interactive seminar presentation at the 2017 Society of Teachers of Family Medicine (STFM) Medial Student Education (MSE) meeting. This was attended by 33 people who identified as either full-time academic faculty, community preceptors, or clerkship coordinators. During the small group breakout session the attendees volunteered to review the competencies with special attention to utility and applicability given their perspectives as family medicine educators. Feedback was used to further enhance clarity of the competencies.
Phase 2, Round 2: The original list of 28 competencies organized in five domains was sent out again as a survey to the cohort of students, residents, medical educators, and physicians who had responded to the initial email and completed the online survey. Of the 106 people who had initially participated, $93 \mathrm{com}$ pleted the survey a second time for a response rate of $88 \%$. Once again, respondents affirmed the previouslyidentified 21 competencies as "very or extremely important."

The final consensus reached through our modified Delphi technique application is a list of $21 \mathrm{com}$ petencies. These encompass the key teaching concepts of commitment to the learner's success, communication, role modeling, feedback, and use of evidence-based medicine (Table 1).

Table 1: Teaching Competencies for Community Physicians

\begin{tabular}{|c|c|c|}
\hline Domain & Goal & Competencies \\
\hline $\begin{array}{l}\text { Learner } \\
\text { centeredness }\end{array}$ & $\begin{array}{l}\text { Demonstrate a } \\
\text { commitment to the } \\
\text { learners' success and } \\
\text { well-being leading } \\
\text { to the learners' } \\
\text { growth in to their } \\
\text { professional roles. }\end{array}$ & $\begin{array}{l}\text { 1. Prepare the clinical environment, including staff, patients, and other } \\
\text { colleagues, for the learner. } \\
\text { 2. Orient the learner to the community, to local resources, and to the clinical } \\
\text { environment. } \\
\text { 3. Ascertain each learner's knowledge, skills and attitudes related to rotation } \\
\text { expectations and link to your patient's/clinic population. } \\
\text { 4. Assess and respond to the learner's cultural context. } \\
\text { 5. Help learners develop learning goals aligned with patients' needs. }\end{array}$ \\
\hline $\begin{array}{l}\text { Interpersonal } \\
\text { and } \\
\text { communication } \\
\text { skills }\end{array}$ & $\begin{array}{l}\text { Teach and } \\
\text { communicate } \\
\text { effectively. }\end{array}$ & $\begin{array}{l}\text { 1. Clearly communicate expectations to the learner. } \\
\text { 2. Tailor precepting style to the needs of the learner. } \\
\text { 3. Identify barriers to learning (eg, housing, geography, psychological, economic, } \\
\text { family, etc). } \\
\text { 4. Maintain a safe learning environment for the student (ie, approachable, } \\
\text { supportive, encouraging, student can admit limitations). }\end{array}$ \\
\hline $\begin{array}{l}\text { Professionalism } \\
\text { and role } \\
\text { modeling }\end{array}$ & $\begin{array}{l}\text { Demonstrate } \\
\text { best educational } \\
\text { and evidence- } \\
\text { based practices } \\
\text { and role model } \\
\text { those behaviors for } \\
\text { learners. }\end{array}$ & $\begin{array}{l}\text { 1. Display enthusiasm for teaching. } \\
\text { 2. Respectfully respond to each learner's unique needs and learning goals } \\
\text { related to patient care. } \\
\text { 3. Be available and accessible to learners. } \\
\text { 4. Acknowledge when beliefs/attitudes are influencing the teaching/learning } \\
\text { environment. } \\
\text { 5. Model highest standards of the profession. }\end{array}$ \\
\hline $\begin{array}{l}\text { Practice-based } \\
\text { reflection and } \\
\text { improvement }\end{array}$ & $\begin{array}{l}\text { Role model } \\
\text { continuous self- } \\
\text { assessment and } \\
\text { lifelong learning. }\end{array}$ & $\begin{array}{l}\text { 1. Model the appropriate use of evidence-based medicine in clinical practice. } \\
\text { 2. Seek feedback from the learner and rotation director; identify and act on } \\
\text { improvement goals. } \\
\text { 3. Engage in continuous learning as physician and teacher with targeted } \\
\quad \text { teaching goals. }\end{array}$ \\
\hline $\begin{array}{l}\text { Learner } \\
\text { assessment }\end{array}$ & $\begin{array}{l}\text { Provide appropriate } \\
\text { feedback. }\end{array}$ & $\begin{array}{l}\text { 1. Solicit student self-assessment. } \\
\text { 2. Provide timely formative and actionable feedback to the learner regarding } \\
\text { their progress (eg, learning goals; rotation competencies; knowledge, skills, } \\
\text { and attitudes). } \\
\text { 3. Check that formative feedback was heard and understood and that the } \\
\text { learner initiated a feasible action plan. } \\
\text { 4. Provide summative feedback to the learner and the medical institution. }\end{array}$ \\
\hline
\end{tabular}




\section{Discussion}

Designing an educational intervention begins with a needs assessment informed by the expected competencies and observable behaviors needed by a person to perform a task-in this case community preceptors of medical students. Using this modified Delphi process, we have identified five community preceptor competency domains and 21 associated competencies for use in preceptor needs assessment, development, and evaluation activities.

Getting consensus on an issue is not easy. Commonly used consensus methods include brainstorming, nominal group technique, consensus development conferences and the Delphi technique. ${ }^{27,28}$ We chose to utilize a modified Delphi technique as a rigorous, semiquantitative method to arrive at a consensus on this important question. While the Delphi process can lead to a "lowest common denominator"29 result rather than a robust product, the breadth of audiences, stakeholders, and rounds in our process supports the validity of our findings.

Still, this list of competencies is not without its limitations. While the resulting product is meant to be broadly applicable to community preceptors of medical students in the various disciplines that make up medicine, the final list of five competency domains and 21 associated competencies may be skewed to the needs of family medicine preceptors as data was obtained through stakeholder audiences predominantly associated with family medicine. Also, all of our participants who completed the two phases of the modified Delphi process were associated with one of three medical schools in Minnesota and Wisconsin. We endeavored to find broader consensus beyond our own medical schools by getting external validation from physicians and clerkship coordinators attending a national meeting on medical student education (the 2017 STFM MSE meeting in Anaheim, CA). Still, broader sampling in other parts of the country and in other primary care and medical specialties would need to occur for greater generalizability. Finally, while developing teaching competencies was the focus of this effort, the teaching competency of the community preceptor is not the only factor that affects students' experiences. Medical scope of practice, ${ }^{30}$ patient population (eg, underserved, immigrant, etc), ${ }^{31}$ degree of patient contact/autonomy, ${ }^{32}$ and length of the clerkship ${ }^{33}$ are also important variables that affect a student's perception of the clerkship and influence a student's interest in the specialty. These issues also need to be considered and addressed as we seek to give medical students the best possible training during their clerkships.

\section{Conclusion}

Education depends on having clearly defined target performance expectations. Well defined lists of competencies exist for various medical educators. ${ }^{21,22}$ Building on this work using a modified Delphi process, we have developed a list of five competency domains and 21 associated competencies to assess preceptor needs, support preceptor development, and evaluate progress toward teaching excellence.

ACKNOWLEDGMENTS: A preliminary version of the completed list of competencies and observable behaviors was presented at the 2017 STFM Medical Student Education Conference; February 9-12, 2017, Anaheim, CA.

CORRESPONDENCE: Address correspondence to Dr Brink, 8381A Family Med/Community Health, MMC 381 Mayo, 516 Delaware St SE, Minneapolis, MN 55455. 651-227-6551. Fax: 612-624-2613.drbrink@umn.edu.

\section{References}

1. Fields SA, Usatine R, Stearns JA, Toffler WL, Vinson DC. The use and compensation of community preceptors in U.S. medical schools. Acad Med. 1998;73(1):95-97.

2. Irby DM. Where have all the preceptors gone? Erosion of the volunteer clinical faculty. West J Med. 2001;174(4):246.

3. Carney PA, Eliassen MS, Pipas CF, Genereaux $\mathrm{SH}$, Nierenberg DW. Ambulatory care education: how do academic medical centers, affiliated residency teaching sites, and community-based practices compare? Acad Med. 2004;79(1):69-77.
4. Starr S, Ferguson WJ, Haley H-L, Quirk M. Community preceptors' views of their identities as teachers. Acad Med. 2003;78(8):820-825.

5. Zinsmeister CS, Siu AL. Clinical teaching by voluntary faculty. Acad Med. 1993;68(5):355356.

6. Drowos J, Baker S, Harrison SL, Minor S, Chessman AW, Baker D. Faculty Development for Medical School Community-Based Faculty: A Council of Academic Family Medicine Educational Research Alliance Study Exploring Institutional Requirements and Challenges. Acad Med. 2017;92(8):1175-1180.

7. Latessa R, Beaty N, Colvin G, Landis S, Janes C. Family medicine community preceptors: different from other physician specialties? Fam Med. 2008;40(2):96-101.

8. Erikson C, Hamann R, Levitan T, Stanley J, Whatley M. Recruiting and maintaining US clinical training sites: joint report of the 2013 multi-discipline clerkship/clinical training site survey. 2014. https://members.aamc.org/eweb/ upload/13-225wcreport2update.pdf. Accessed July 26, 2017.

9. Lacroix TB. Meeting the need to train more doctors: the role of community-based preceptors. Paediatr Child Health. 2005;10(10):591594.

10. Roberts K, DeWitt T. Faculty development of pediatric practitioners: complexities in teaching clinical precepting. Pediatrics. 1996. http:// pediatrics.aappublications.org/content/97/3/389. short. Accessed March 27, 2017.

11. Levy BT, Gjerde CL, Albrecht LA. The effects of precepting on and the support desired by community-based preceptors in Iowa. Acad Med. 1997;72(5):382-384.

12. Langlois JP. Support of community preceptors: what do they need? Fam Med. 1995;27(10):641645 .

13. Irby D, Bowen J. Time-efficient strategies for learning and performance. Clin Teach. 2004;1(1):23-28.

14. Gjerde CL, Hla KM, Kokotailo PK, Anderson B. Long-term outcomes of a primary care faculty development program at the University of Wisconsin. Fam Med. 2008;40(8):579-584.

15. Christner JG, Dallaghan GB, Briscoe G, et al. The community preceptor crisis: recruiting and retaining community-based faculty to teach medical students-a shared perspective from the Alliance for Clinical Education. Teach Learn Med. 2016;28(3):329-336.

16. James PA, Osborne JW. A measure of medical instructional quality in ambulatory settings: the MedIQ. Fam Med. 1999;31(4):263-269.

17. James PA, Kreiter CD, Shipengrover J, Crosson J. Identifying the attributes of instructional quality in ambulatory teaching sites: a validation study of the MedEd IQ. Fam Med. 2002;34(4):268-273.

18. Press KR, Bodurtha J. Milestones for medical students completing a clinical genetics elective. Genet Med. 2017;19(2):236-239.

19. Santen SA, Peterson WJ, Khandelwal S, House JB, Manthey DE, Sozener CB. Medical student milestones in emergency medicine. Acad Emerg Med. 2014;21(8):905-911. 
20. Accreditation Council for Graduate Medical Education. ACGME list of milestones for each residency. http://www.acgme.org/Specialties. Accessed December 1, 2016.

21. Srinivasan M, Li S-TT, Meyers FJ, et al. "Teaching as a Competency": competencies for medical educators. Acad Med. 2011;86(10):12111220.

22. Görlitz A, Ebert T, Bauer D, et al; GMA Committee on Personal and Organizational Development in Teaching. Core competencies for medical teachers (KLM)-a position paper of the GMA committee on personal and organizational development in teaching. GMS Z Med Ausbild. 2015;32(2):Doc23.

23. de Villiers MR, de Villiers PJT, Kent AP. The Delphi technique in health sciences education research. Med Teach. 2005;27(7):639-643.

24. Linstone H, Turoff M, eds. The Delphi Method: Techniques and Applications. Reading; MA Addison-Wesley; 1975

25. Lindemann CA. Priorities Within the Health Care System: A Delphi Survey. Kansas City, MO: American Nurses' Association; 1981.
26. Custer R, Scarcella J, Stewart B. The Modified Delphi Technique--a rotational modification. J Vocat Tech Educ. 1999;15(2):50-58.

27. Waggoner J, Carline JD, Durning SJ. Is there a consensus on consensus methodology? Descriptions and recommendations for future consensus Research. Acad Med. 2016;91(5):663-668.

28. Jones J, Hunter D. Consensus methods for medical and health services research. BMJ. 1995;311(7001):376-380.

29. Rennie D. Consensus statements. N Engl J Med. 1981;304(11):665-666.

30. Anthony D, White J, Margo K, Tarn DM. Scope of practice and family medicine match rates: results from a CERA clerkship directors' survey. Fam Med. 2017;49(3):177-182. Accessed November 30, 2017.

31. Knox KE, Getzin A, Bergum A, McBride P, Rieselbach R, Friedsam D. Short report: factors that affect specialty choice and career plans of Wisconsin's medical students. WMJ. 2008;107(8):369-373.
32. Kandiah DA. Perception of educational value in clinical rotations by medical students. Adv Med Educ Pract. 2017;8:149-162.

33. Konkin DJ, Suddards C. Students' experiences of role, relationships and learning in two clerkship models. Med Educ. 2017;51(5):490-497. 